\title{
Untangling the bilateral versus single internal mammary coronary artery bypass grafting debate
}

\author{
Emile Voisine", Pierre Voisine ${ }^{\#}$ \\ Department of Cardiology, Institut Universitaire de Cardiologie et de Pneumologie de Québec (IUCPQ), Québec City, Québec, Canada \\ \#These authors contributed equally to the work. \\ Correspondence to: Pierre Voisine. Institut Universitaire de Cardiologie et de Pneumologie de Québec (IUCPQ), 2725 chemin Ste-Foy, L3576, \\ Québec, QC, G1V 4G5, Canada. Email: pierre.voisine@chg.ulaval.ca. \\ Provenance: This is a Guest Editorial commissioned by Section Editor Busheng Zhang, PhD, MD (Department of Cardiac Surgery, Shanghai Chest \\ Hospital, Shanghai Jiao Tong University, Shanghai, China). \\ Comment on: Iribarne A, Schmoker JD, Malenka DJ, et al. Northern New England Cardiovascular Disease Study Group. Does Use of Bilateral \\ Internal Mammary Artery Grafting Reduce Long-Term Risk of Repeat Coronary Revascularization? A Multicenter Analysis. Circulation \\ 2017;136:1676-85.
}

Submitted Mar 01, 2018. Accepted for publication Mar 06, 2018.

doi: 10.21037/atm.2018.03.21

View this article at: http://dx.doi.org/10.21037/atm.2018.03.21

Numerous retrospective studies have previously shown that patients receiving bilateral internal mammary artery (BIMA) when undergoing coronary artery bypass grafting (CABG) have a better long-term survival than patients receiving single internal mammary artery (SIMA) (1-3). However, much less data is available with respect to the need for repeat revascularization in these groups. In light of this, the study led by Iribarne et al. and published in Circulation in October 2017 set out to determine whether timing, frequency and type of such repeat revascularization was different in patients receiving BIMA and SIMA (4).

Iribarne et al. examined 47,984 patients undergoing CABG between 1992 and 2014. Among these, 1,482 patients ( $3.1 \%$ of the total population) having undergone BIMA surgery were compared to a propensity-matched equal number of SIMA patients from the larger pool of patients. After a median follow-up of 13.2 years, more patients receiving SIMA (19.4\%) required repeat revascularization after their initial surgery than patients receiving BIMA (15.1\%, $\mathrm{P}=0.004)$. SIMA was also associated with higher allcause mortality at 12 years compared to BIMA.

This article by Iribarne et al. proves noteworthy on many fronts. It provides a clear, statistically strong and long-ranging picture of its subject, as it studied a large population $(2,964$ patients) over a long period of time (13.2 years median follow-up), using a sound methodology that yielded clear-cut and statistically significant results. Moreover, its retrospective nature and all-comers registry analysis afford a real-world perspective on the issue of SIMA vs. BIMA, which may ring truer to clinicians and serve as a stronger basis for considering clinical practice changes. On the flipside, the study is also limited, most importantly by that same retrospective nature and by its use of propensity matching. Given the greater complexity and expected peri-operative physical toll of BIMA grafting surgery, it could be assumed that it is chosen more often for lower-risk patients and those deemed to have longer life expectancy. When reviewing early post-operative data, a selection bias indeed seems to have favoured the BIMA group: the unadjusted in-hospital mortality and the rate of stroke are double in the SIMA group, post-operative stay is generally higher for SIMA patients and, after the propensity-match, the median number of grafts used is higher in BIMA patients than in SIMA patients. However the percentage of revascularization is the same in both groups. Another limitation is that propensity matching only accounts for what is included in its matching from the getgo. Unfortunately, a few important post-operative variables could not be taken into account by this matching, namely frailty of the patient, quality of bypass targets, quality of vein and arterial conduits, economic status, compliance with medication and secondary prevention after CABG, as 
pointed out in a recent editorial on the article published in Circulation (5). Given that some of these variables could be markedly different between groups, their inclusion would have allowed for better analysis of the results. On another front, the BIMA patients included in Iribarne et al.'s study only represent a small fraction of the overall population of patients having undergone CABG (3.19\%) in the centers participating in the study, which does not reflect the proportion of BIMA patients United States-wide (it increased from 3.5\% to $4.1 \%$ between 1999 and 2009). This calls into question the generalization of the study's findings to the larger target population. Finally, Iribarne et al. do not provide a breakdown of how many patients in each group received an additional radial-artery graft, which is known to be superior to single mammary-artery grafting (6). This not only complicates internal comparison of the BIMA and SIMA groups, but also prevents readers from efficiently comparing this study to others that might include the radial-artery graft breakdown.

Iribarne et al.'s findings are made all the more important by the fact that they come a few months after the publication in The New England Fournal of Medicine of an article by Taggart et al. that has been interpreted as contradictory and has unwillingly stirred a certain controversy (7). This article reports the 5 -year interim analyses of a study planned to have a 10 -year follow-up period. It is the first of its randomized and prospective nature to describe SIMA vs. BIMA. The authors set out to compare death from any cause and a composite of death from any cause, myocardial infarction or stroke at 10 years. They found that at the midpoint of this study period, there is no significant difference between SIMA and BIMA when it comes to the study's endpoints: SIMA and BIMA appear to have a similar rate of death $(8.4 \%$ vs. $8.7 \%$ respectively, $\mathrm{P}=0.77$ ) and both groups were also found to have a similar rate of the composite of death from any cause, myocardial infarction or stroke (12.7\% vs. $12.2 \%$ respectively, $\mathrm{P}=0.69)$. Moreover, and perhaps more importantly when considering the study led by Iribarne et al., when observing adverse events following the surgery, Taggart et al. found that the need for repeat revascularization was nearly identical in both the SIMA and BIMA groups (6.6\% vs. $6.5 \%, \mathrm{P}=0.91)$. Another significant finding of this study was that the rate of sternal wound complications and reconstruction was significantly lower in the SIMA group than in the BIMA group. This is in contradiction with Iribarne et al.'s study where sternal wound complications did not differ in SIMA and BIMA groups, but their observation period only covered the index hospitalization. Given that such complications often arise later in the postoperative period, Iribarne et al.'s study would have benefited from the longer, 1-year observation period of Taggart et al.'s. The added depth of information and additional point of comparison provided would only have strengthened the study.

Despite caution exerted by Taggart et al. about drawing significant conclusions from their interim analyses, the erroneous message of there being no difference between SIMA and BIMA is unfortunately spreading (8). It is because of this rising controversy that the article by Iribarne et al. cannot be discussed without also carefully considering Taggart et al.'s.

Because of its methodology and of its novelty, Taggart et al.'s study is obviously noteworthy and valuable. It is the first randomized prospective study to compare SIMA and BIMA groups, and the patients composing these groups are otherwise very similar, despite originating from 28 different hospitals in seven countries. However, it is not without flaws, which make the conclusions being drawn from it, as well as the possible reduced use of BIMA that may ensue, premature at best. Chief among these flaws is the insufficient number of years at risk, given that the interim analyses only come after 5 years out of the planned 10 years of follow-up. For this reason alone, the results should be considered carefully, not only because they come from interim analyses, but also because at this stage of their study, Iribarne et al. had similar results. Indeed, the significant differences in need for repeat vascularization only started to appear after 8 to 10 years. This is also consistent with previous literature on the matter. Therefore, it is possible that similar differences will start to appear further down the line in the study by Taggart et al. Other limitations also support being cautious in drawing early conclusions from the article. First, $20 \%$ of the SIMA group in the Taggart et al. study received an additional radial-artery graft, which is known to be superior to single mammaryartery grafting (6) and may have positively influenced the results in the SIMA group. Second, patients in the Taggart et al. study were generally older, with more than $25 \%$ of them being aged over 70, while the use of BIMA for older patients is controversial $(9,10)$. This could have negatively impacted the results in the BIMA group. Third, sicker patients have been shown to benefit more from BIMA $(11,12)$, and patients enrolled in the Taggart et al. study are generally healthy, which again could have altered the overall results. Also, the study provides no evidence of control for graft patency being performed. Given that BIMA is a 
longer and more complex surgery, the potential for it being technically less successful is higher. Finally, high crossover rates were observed in the BIMA group, as $16 \%$ of patients initially assigned to receive BIMA actually received SIMA. This lowers the statistical power of the study and further compromises the conclusions being drawn from its results. All these limitations are acknowledged and addressed by Taggart et al., either in the article itself or in subsequent correspondence with critics of their study (13). Again, the premature conclusions being drawn from the article are out of the authors' hands.

Despite its limitations, the study by Iribarne et al. is well performed and has sound methodology. In addition to it being in accordance with previous studies' findings on the matter of SIMA vs. BIMA, this makes their findings all the more valid. Until proof of the contrary is made, BIMA grafting should be considered superior to SIMA grafting in patients undergoing CABG and able to withstand a slightly longer, more complex surgery. Unfortunately, because of their aforementioned significant limitations, the interim results presented in Taggart et al.'s study do not constitute, for now, a good enough proof of that contrary. However, being the first prospective randomized study to consider SIMA vs. BIMA, it shows great promise, and the results it will present after its 10 -year observation period is completed should shed further light on the matter.

\section{Acknowledgements}

None.

\section{Footnote}

Conflicts of Interest: The authors have no conflicts of interest to declare.

\section{References}

1. Yi G, Shine B, Rehman SM, et al. Effect of bilateral internal mammary artery grafts on long-term survival: a meta-analysis approach. Circulation 2014;130:539-45.

2. Takagi H, Goto SN, Watanabe T, et al. A meta-analysis of adjusted hazard ratios from 20 observational studies of bilateral versus single internal thoracic artery coronary artery bypass grafting. J Thorac Cardiovasc Surg 2014;148:1282-90.

3. Lytle BW, Blackstone EH, Loop FD, et al. Two internal thoracic artery grafts are better than one. J Thorac
Cardiovasc Surg 1999;117:855-72.

4. Iribarne A, Schmoker JD, Malenka DJ, et al. Northern New England Cardiovascular Disease Study Group.

Does Use of Bilateral Internal Mammary Artery Grafting Reduce Long-Term Risk of Repeat Coronary Revascularization? A Multicenter Analysis. Circulation 2017;136:1676-85.

5. Sellke FW. Bilateral Versus Single Internal Mammary Artery Bypass Grafting: Do We Have the Answer? Circulation 2017;136:1686-7.

6. Cao C, Ang SC, Wolak K, et al. A meta-analysis of randomized controlled trials on mid-term angiographic outcomes for radial artery versus saphenous vein in coronary artery bypass graft surgery. Ann Cardiothorac Surg 2013;2:401-7.

7. Taggart DP, Altman DG, Gray AM, et al. Randomized Trial of Bilateral versus Single Internal-Thoracic-Artery Grafts. N Engl J Med 2016;375:2540-9.

8. Di Mario C, Sorini Dini C, Wijns W. The year in cardiology 2016: coronary interventions. Eur Heart J 2017;38:1017-27.

9. Mohammadi S, Dagenais F, Voisine P, et al. Lessons learned from the use of 1,977 in-situ bilateral internal mammary arteries: a retrospective study. J Cardiothorac Surg 2014;9:158.

10. Gideon S, Meir A, Battler A, et al. Bilateral skeletonized internal mammary versus single-pedicled internal mammary grafting in the elderly. Isr Med Assoc J 2007;9:294-8.

11. Lytle BW, Blackstone EH, Sabik JF, et al. The effect of bilateral internal thoracic artery grafting on survival during 20 postoperative years. Ann Thorac Surg 2004;78:200512; discussion 2012-4.

12. Raza S, Sabik JF 3rd, Masabni K, et al. Surgical revascularization techniques that minimize surgical risk and maximize late survival after coronary artery bypass grafting in patients with diabetes mellitus. J Thorac Cardiovasc Surg 2014;148:1257-64; discussion 1264-6.

13. Angouras DC, Royse A, Eccleston D, et al. Correspondence on Bilateral versus single internalthoracic-artery grafts. N Engl J Med 2017;376:e37.

Cite this article as: Voisine E, Voisine P. Untangling the bilateral versus single internal mammary coronary artery bypass grafting debate. Ann Transl Med 2018;6(10):190. doi: 10.21037/ atm.2018.03.21 